\title{
Shifting genetic patterns in anencephaly and spina bifida
}

\author{
DWIGHT T. JANERICH AND JOYCE PIPER
}

From New York State Department of Health, Cancer Control Bureau, Albany, N.Y. 12237, U.S.A.

SUMMARY The long-term decline in the incidence of the neural tube malformations, anencephaly and spina bifida (ASB), ended in the mid-1950's in New York State. Since that time, the rate of these birth defects has remained between 1 and $1 \cdot 5 / 1000$ births. In this low incidence population, we tested the basic tenets which support a genetic aetiology. We found that the full sib recurrence rate $(1.8 \%)$ was higher than the half sib recurrence rate $(0.8 \%)$ and the twin concordance rate $(6.8 \%)$ was higher than the full sib recurrence rate. We found the incidence of ASB in twins to be the same as the incidence of ASB in singletons. Our findings are compatible with polygenic inheritance aetiology for ASB. The genetic molecular pathway of these birth defects may be identifiable through biochemical screening of families with one or more ASB children.

Our composite view of the epidemiology and genetics of anencephaly and spina bifida (ASB) has been synthesised from a large assortment of studies done primarily in American and British populations. Within this composite are a number of troublesome inconsistencies which present obstacles to the development of a comprehensive aetiological hypothesis. For example, one major study suggested that ASB twin concordance (both twins affected) is less frequent than recurrence among full sibs (Yen and MacMahon, 1968) while several other studies find no noteworthy deficiency in concordant twin pairs (Gittelsohn and Milham, 1965; Naggan, 1971; Carter and Evans, 1973). Another important inconsistency among genetic data indicates that the recurrence rate in half sibs (children with one parent in common), or at least in maternal half sibs, is as great as the recurrence rate in full sibs (Yen and MacMahon, 1968). In theory, the recurrence rate should be less among half sibs (McMahon and Pugh, 1970). Paradoxical observations such as these need to be explained before a comprehensive aetiological hypothesis can evolve.

One of the most significant recent changes in our understanding of the aetiology of ASB is the retrospective discovery that an epidemic of ASB occurred during the first half of this century in the northeastern United States (MacMahon and Yen, 1971) and in Britain (Rogers and Morris, 1971). Many of the important early inheritance studies included data from

Received for publication 15 June 1977 the time of the epidemic, but these studies were done before we were aware of the epidemic's existence. Therefore, a number of earlier studies which provided the descriptive genetic data on ASB had been inadvertently conducted during a time when environmental factors had a major influence on its occurrence. Our report is an attempt to present an adjusted view of the genetics of ASB in the light of the epidemic. The data are from a series of family studies conducted in New York State during the postepidemic era.

The analysis focuses on the most simple and direct measures of disease inheritance; recurrence among full sibs, recurrence among half sibs, and twin concordance. The concept of polygenic inheritance is the basic genetic hypothesis for ASB, and it predicts that a ranked hierarchy of recurrence risk should exist among twins, full sibs, and half sibs as the result of a ranked dilution of shared genes within these sib relationships. Full sib recurrence should be intermediate between twin concordance rates and half sib recurrence rates, according to this concept.

\section{Methods}

The source for data used for this study was birth and fetal death certificates ( $\geqslant 28$ weeks of gestation) from the post-epidemic period in Upstate New York (all of New York exclusive of New York City). ASB is well reported in vital records (Hay, 1971). We used the two conventional subgroupings of ASB to classify cases; 
'anencephaly' including craniorrhachischisis (the two defects combined), and 'spina bifida' which includes all other cases of meningocele, myelocele, and encephalocele.

Full sib information was obtained from two sources: interviews with 208 mothers of children born with ASB during 1970 to 1972; and a systematic search for birth and fetal death records to identify any sibs of 420 ASB index cases born during 1956 to 1960. The first affected child found in a family unit to have been born during the studied years (1956 to 1960 and 1970 to 1972) was designated as the index case. Any other affected sib born during the studied years was excluded as an index case and categorised as a sib recurrence. The maternal interview series identified 415 full sibs and the systematic record search indentified an additional 622 full sibs. Recurrence rates were similar from both sources and the data pooled. All index cases and their full sibs were born after 1955.

Half sibs of ASB index cases were identified through systematic vital record linkage. When the marriage record of the parents of a child born with ASB indicated that either spouse had had a prior marriage, we systematically searched for a birth or fetal death record of any offspring from that marriage. This effort identified 133 half sibs of ASB index cases.

Twin data include all multiple birth events from 1961 to 1974 . Twin concordance rates were calculated in the same way as sib recurrence rates. Twin data on ASB in New York State from 1950 to 1960 were reported previously (Gittelsohn and Milham, 1965). Twin pairs which the birth record identified as concordant were checked through the medical record department of the certifying hospital. This verification procedure caused the reclassification of one twin pair which had been incorrectly classified as concordant on the original birth record.

\section{Results}

\section{INCIDENCE}

The time limits of the epidemic must be established retrospectively from the changes in the secular rate of ASB. In New England, MacMahon and Yen concluded that the epidemic reached its peak at about 1930, with a rate of 7 cases of ASB per 1000 births, and had ended in 1950 when the rate had reached a level of 2 to 3 per 1000 (MacMahon and Yen, 1971). In New York, the rate continued to decline until about 1955. In the last two decades (1955 to 1974) the rate has remained in the range of 1 to 1.5 per 1000 . During that period the rates of anencephaly and spina bifida have remained approximately equal and parallel (Janerich, 1973a).

The precise end of the epidemic is difficult to recognise or estimate. In relative terms, the post-1955 rate tends to be stable and appears to be approaching a baseline level of about 1 case of ASB per $1000^{\circ}$ births, and the rapid rate changes which characterised? the epidemic had clearly disappeared by $1955 \vec{F}$ Therefore, it seems reasonable to assume that the? epidemic had ended in New York State sometimeduring the early to mid-1950's.

\section{FULL SIBS}

We identified a total of 1037 full sibs for our 628 indexis cases. Nineteen of these sibs were affected (Table 1). $\vec{\circ}$ The percentage of affected sibs was the same whether. the index case had anencephaly or spina bifida $(1.8 \%) \cdot \vec{\omega}$ Sibs born before the index case were more frequentlye affected than subsequent sibs. A higher rate among prior sibs agrees with recent findings from $a$ neighbouring population in the northeastern United States (Holmes et al., 1976). In both studies the recurrence risk among subsequent sibs of an ASBO index case was less than $2 \%$, and this implies that the chance of ASB recurrence in this part of the world is $1^{-}$ in 50 instead of 1 in $20(5 \%)$ which is traditionally $\vec{D}$ quoted and is based primarily on British studies.

In addition to our study and the other recent study. (Holmes et al., 1976), one family study (Yen and $\overrightarrow{0}$ MacMahon, 1968), and two epidemiological cohorpo studies (Janerich, 1972; Janerich, 1973b), all show some form of progressive decline in the risk of ASB ass the birth order and/or parental age increases. This group of studies covers a range of population rates and it seems that this pattern of progressive diminish $-\bar{D}$ ing risk is one of the more constant features of $\mathrm{ASB}^{2}$ recurrence. Further study is needed before we canê understand the cause of this pattern, but it has two immediate and important effects on genetic counsell? ing. First, empirical recurrence risks can no longer be calculated for a population by pooling recurrence rates among sibs born before and after an index case because this practice produces an erroneously high risk estimate. Second, efficiency or effectiveness estimates for prenatal testing of women who have had? a prior ASB child will need to be adjusted, because the recurrence risk among subsequent sibs is lower than the overall risk which was used as the basis of previous recurrence estimates.

Table 1 Recurrence risk (\%) of spina bifida and anencephaly among prior and subsequent sibs

\begin{tabular}{llll}
\hline $\begin{array}{l}\text { Malformation in } \\
\text { index case }\end{array}$ & Prior sibs & $\begin{array}{l}\text { Subsequent } \\
\text { sibs }\end{array}$ & Total \\
\hline Anencephaly & $3 / 107$ & $5 / 327$ & $8 / 434$ \\
Spina bifida & $(2.8 \%)$ & $(1.5 \%)$ & $(1.8 \%)$ \\
Total & $6 / 188$ & $5 / 415$ & $11 / 603$ \\
& $(3.2 \%)$ & $(1.3 \%)$ & $(1.8 \%)$ \\
\hline & $9 / 295$ & $10 / 742$ & $19 / 1041$ \\
& $(3.1 \%)$ & $(1.4 \%)$ & $(1.8 \%)$ \\
\hline
\end{tabular}

* Adjusting for 3 families with complete ascertainment $(22 / 1041=2 \cdot 1 \%)$ 
Table 2 Recurrence of $A S B$ in half sibs

\begin{tabular}{|c|c|c|c|c|c|}
\hline & $\begin{array}{l}\text { (Carter et al., } \\
1968 \text { ) }\end{array}$ & $\begin{array}{l}\text { (Yen and } \\
\text { MacMahon, 1968) }\end{array}$ & $\begin{array}{l}\text { (Carter and } \\
\text { Evans, 1973) }\end{array}$ & $\begin{array}{l}\text { Present } \\
\text { Study NY }\end{array}$ & Total \\
\hline Maternal half sibs & 34 & 23 & 115 & 82 & 254 \\
\hline No. affected & 0 & $3(13 \%)$ & $3(2.6 \%)$ & $1(1 \cdot 2 \%)$ & $7(2.8 \%)$ \\
\hline Paternal half sibs & 18 & - & 84 & $5 i$ & 153 \\
\hline No. affected & 0 & - & $1(1 \cdot 2 \%)$ & 0 & $1(0.7 \%)$ \\
\hline Total sibships & NA & 7 & 86 & 61 & - \\
\hline Total half sibs & 52 & 23 & 199 & 133 & 407 \\
\hline No. affected & $0(0 \%)$ & $3(13 \%)$ & $4(2.0 \%)$ & $1(0.8 \%)$ & $8(2.0 \%)$ \\
\hline
\end{tabular}

\section{HALF SIBS}

Table 2 summarises our findings on half sib recurrence together with the findings of the three previous reports which included similar data (Carter et al., 1968; Yen and MacMahon, 1968; Carter and Evans, 1973). Among the 133 half sibs we identified, only one was affected and the recurrence risk was $0.8 \%$. The only other study reported from the U.S. found a very high recurrence risk of $13 \%$ and was based on 3 affected half sibs among the 23 maternal half sibs which the investigators had identified (Yen and MacMahon, 1968). Each of the other studies found a half sib recurrence risk which was lower than the recurrence risk ordinarily found in full sibs (Carter et al., 1968; Carter and Evans, 1973). In general, the findings of the latter studies tend to be consistent with the polygenic inheritance expectation. The contrary findings of the previous U.S. study may have been influenced by the epidemic, which had not yet been recognised when the half sib data were reported.

TWINS

During 1961 to 1974 there were 23310 twin pairs

Table 3 Affected twin pairs, New York birth records 1961-1974

\begin{tabular}{|c|c|c|c|c|}
\hline & \multicolumn{2}{|c|}{ Like sex } & \multicolumn{2}{|l|}{ Unlike sex } \\
\hline & $M-M$ & $F-F$ & $M$ affected & $F$ affected \\
\hline \multicolumn{5}{|l|}{ Anencephaly } \\
\hline discordant & 10 & 9 & 5 & 4 \\
\hline concordant & - & $3 *$ & - & - \\
\hline \multicolumn{5}{|l|}{ Spina bifida } \\
\hline discordant & 7 & 15 & 2 & 3 \\
\hline concordant & 0 & 1 & - & - \\
\hline Total sets & 17 & 28 & $7+$ & 7 \\
\hline
\end{tabular}

-Includes one pair with anencephaly in one twin and spina bifida in the other. tOne pair excluded: male anencephalic, female macerated stillbirth.
(46 620 individuals) born in New York State and 63 individuals among these had ASB. The 63 individuals come from four pairs which were concordant and 55 pairs which were discordant for ASB. This is an overall rate of 1.4 per 1000 births $(63 / 46620)$-and is the same as the rate in singletons. Therefore, the frequency of ASB among twins was not unusual or remarkable.

Concordance and discordance among twins is the most important relation in twin studies, and the concordance pattern among our 59 affected twin pairs is shown in Table 3. Like most family studies of ASB, we rely on a statistical assessment of twin zygosity. Simply stated, this means we assume a portion of the like-sex twins are monozygous.

All 4 concordant twin pairs in our study were like-sex. One pair in which the male was anencephalic and the second member described as a macerated stillbirth reported as female has been excluded. In simple recurrence terms, among these 59 twin pairs we found 4 co-members affected. Four out of 59 is a recurrence risk of $6.8 \%$, which is substantially higher than the $1.8 \%$ recurrence risk among full sibs. Assuming that some portion of our like-sex twin pairs are monozygotic, the concentration of concordant twin pairs among the like-sex group is consistent with a genetic aetiology-probably polygenic. Using the Hardy Weinberg estimate for statistical assessment of zygosity indicates that $52 \%$ ( 31 out of 59 ) of our twin pairs are monozygotic. Our findings do not agree with the earlier report which found a deficit of concordant pairs among twin pairs affected with ASB (Yen and MacMahon, 1968).

POPULATION GENETICS

Table 4 is a summary of recurrence, or concordance, among twins, full sibs, and half sibs from the four

Table 4 Recurrence rate of $A S B$ in sibs in relation to population incidence

\begin{tabular}{|c|c|c|c|c|c|c|c|c|}
\hline \multirow[b]{2}{*}{ Incidence rate of ASB } & \multicolumn{2}{|c|}{$\begin{array}{l}\text { South Wales (Carter } \\
\text { et al., 1968) } \\
1956-62 \\
\text { High endemic }\end{array}$} & \multicolumn{2}{|c|}{$\begin{array}{l}\text { New England (Yen and } \\
\text { MacMahon, 1968) } \\
1936-65 \\
\text { Epidemic }\end{array}$} & \multicolumn{2}{|c|}{$\begin{array}{l}\text { Greater London (Carter } \\
\text { and Evans, 1973) } \\
1965-68 \\
\text { Moderate endemic }\end{array}$} & \multicolumn{2}{|c|}{$\begin{array}{l}\text { New York 1955-74 } \\
\text { Low endemic }\end{array}$} \\
\hline & $7 \cdot 5 / 1000$ & & $5 \cdot 5$ to 1.5 & 00 & $2 \cdot 9 / 1000$ & & $1 \cdot 3 / 1000$ & \\
\hline $\begin{array}{l}\text { Recurrence rate } \\
\text { Among co-twins } \\
\text { Among full sibs } \\
\text { Among half sibs }\end{array}$ & $\begin{array}{l}0 / 13 \\
81 / 1562 \\
0 / 52\end{array}$ & $\begin{array}{r}0 \% \\
5 \cdot 2 \% \\
0 \%\end{array}$ & $\begin{array}{l}0 / 30 \\
58 / 1263 \\
3 / 23\end{array}$ & $\begin{array}{r}0 \% \\
4.6 \% \\
13.0 \%\end{array}$ & $\begin{array}{l}1 / 14 \\
66 / 1484 \\
4 / 199\end{array}$ & $\begin{array}{l}7 \cdot 1 \% \\
4 \cdot 4 \% \\
2 \cdot 0 \%\end{array}$ & $\begin{array}{l}4 / 59 \\
19 / 1037 \\
1 / 133\end{array}$ & $\begin{array}{l}6.8 \% \\
1.8 \% \\
0.8 \%\end{array}$ \\
\hline
\end{tabular}

Adjusting for 3 families with complete ascertainment $22 / 1041=2 \cdot 1 \%$. 
major studies in which data for each sib type were given for a single population. The incidence of ASB in each population differs, and we have characterised each population according to its incidence rate. Data were reported from Wales (Carter et al., 1968) where the incidence rate tends to be high $(7 \cdot 5 / 1000)$. The New England data (Yen and MacMahon, 1968) spanned the second half of the epidemic and the early post-epidemic period and has been characterised as an epidemic pattern. Data reported from London (Carter and Evans, 1973) where the rate of ASB was 2.9/1000 and is intermediate or moderate. Our own data from New York, where the rate was $1 \cdot 3 / 1000$ has been characterised as low.

Although the characterisation of these rates is arbitrary, the ranking of the populations into these categories seems reasonable according to our conventional understanding of the range and variability in ASB incidence rates. More important, this overall ranking seems to lend a sense of order to the observed interrelations between twin concordance, and full and half sib recurrence. In the two populations with moderate or low rates of ASB (London and New York) predictable genetic patterns do occur. In New York, where the incidence is low, the rank order of recurrence rates within sib relationship categories is remarkably compatible with polygenic causation. Severe violation of this ranking occurs only in the population which had an epidemic incidence pattern. Though we do not yet understand why ASB incidence differs between population groups and varies over time, we can conclude that it is only when the ASB rate is low that the pattern predicted by polygenic inheritance is expressed among each type of sib relationship.

\section{Discussion}

The rate of ASB in New York State during the last two decades is among the lowest reported from a predominantly white western population. It is possible that this incidence is approaching a baseline rate for these malformations. At the current level of about 1 case of ASB per 1000 births, the family recurrence ratios between sib types can be easily reconciled with those of a polygenic inherited trait. During periods of time when environmental factors cause epidemic rate patterns, the recurrence ratios differ significantly from the expected pattern of a polygenic trait. These distortions in the sib recurrence ratios are not simply explained, and the form of these changes suggests that adverse environmental factors actually modify the inheritance mechanism rather than magnify it. Since maternal inheritance seems more important during epidemic circumstances, perhaps the environment alters a genetically controlled mechanism in the mother.
Alterations in the sex ratio of anencephalics during $\Omega$ the Birmingham epidemic prompted one investigator (Leck, 1972) to refer to the sex ratio as a labile'? characteristic of ASB. This same term might also be $\vec{F}$ used to describe ASB full sib recurrence risk which $\stackrel{?}{+}$ usually appears to be 10 times the population? incidence (Blyth and Carter, 1969). In a very broad $\frac{\overline{\bar{C}}}{\bar{D}}$ sense, the genetic mechanism underlying ASB seems $\frac{\pi}{7}$ to be rendered labile by an adverse environment. For $\propto$ example, high rates of ASB are associated with $a_{\infty}$ deficiency of concordant twin pairs; but there is no deficiency of twin pairs under more favourable environmental conditions. When the rate of $\mathrm{ASB} \vec{\omega}$ becomes low or perhaps when it reaches a genetically endemic level, the mechanism(s) respon- $\overline{3}$ sible for ASB and twinning tend to coexist in a genetically predictable fashion.

Nance's cytoplasmic gene hypothesis (Nance, 1969) and Knox's twin fetus hypothesis (Knox, 1974), 으 do not provide an explanation for this labile genetic ${ }_{0}$ mechanism. The Nance hypothesis depends on maternal inheritance for ASB, but maternal inheritance $\vec{\supset}$ seems to play a primary role only during epidemico circumstances. A cornerstone of the Knox hypothesis is a deficiency of ASB concordant twins, but in our $\overrightarrow{0}$ data we found no deficiency of concordant twin pairs. Our twin data are also difficult to reconcile with the hypothesis that high rates of ASB are the result of lowered levels of early fetal loss (Roberts and Lloyd, 1973) because it seems reasonable to assume that concordant twin pairs would be more vulnerable toळ early loss, yet, in our population with its low rate, we find a high proportion of concordant twin pairs. Ouro data indicate that the basic cause of ASB is a polygenic, inherited mechanism whose expression is radically modified by adverse environmental conditions.

The data presented here suggest that the environmental elements which produce rates above this 3 assumed baseline level must interfere with the genetic. molecular pathway. We suggest that the next logical $\frac{}{3}$ step to understanding the aetiology of ASB is extensive biochemical screening of high risk families. At present, direct identification of the controlling $D$ genetic loci seems unlikely because we know too little about the molecular pathway. If one accepts polygenic $N$ inheritance as the underlying cause of ASB, it implies that at some baseline level these malformations are 0 unavoidable byproducts of inheritance within ac genetically heterogeneous population. Though the literature contains a few suggestions about possibleo areas for biochemical screening (Hibbard and Smithells, 1965; Wilson and Vallance-Owen, 1966; $\stackrel{\oplus}{+}$ Gal et al., 1972; Janerich, 1974; Smithells et al., 궁 1976), any recommendation limiting the scope of

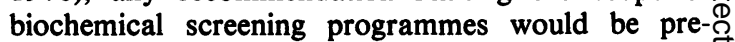
mature. The findings of future familial biochemical $\stackrel{\mathbb{Q}}{\Omega}$ 
studies must be interpreted in relation to the incidence of ASB for that specific population.

This study was funded in part by Grant No. 5R01HD0770 from the National Institute of Child Health and Human Development, National Institutes of Health. The authors wish to thank Mr Charles Gressler and Ms Ellen Burometto for technical assistance.

\section{References}

Blyth, H., and Carter, C. O. (1969). A guide to genetic prognosis in pediatrics. Developmental Medicine and Child Neurology, Suppl. 18 , p. 17.

Carter, C. O., David, P. A., and Laurence, K. M. (1968). A family study of major central nervous system malformations in South Wales. Journal of Medical Genetics 5, 81-106.

Carter, C. O., and Evans, K. (1973). Spina bifida and anencephaly in Greater London. Journal of Medical Genetics 10, 209-234.

Gal, I., Sharman, I. M., and Pryse-Davies, J. (1972). Vitamin A in relation to human congenital malformations. Advances in Teratology 5, 143-159.

Gittelsohn, A. M., and Milham, S. (1965) Vital records of congenital malformations in New York State. In Genetics and Epidemiology of Chronic Disease, pp. 305-319. Ed. by J. V. Neel, M. W. Shaw, and W. J. Schull. United States Department of Health, Education and Welfare, Public Health Service, Division of Chronic Diseases, Washington, D.C. (PHS Publication No. 1163).

Hay, S. (1971). Incidence of selected congenital malformation in Iowa. American Journal of Epidemiology, 94, 572-584.

Hibbard, E. D., and Smithells, R. W. (1965). Folic acid metabolism and human embryopathy. Lancet, 1, 1254.

Holmes, L., Driscoll, S., and Atkins, L. (1976). Etiologic heterogeneity of neural tube defects. New England Journal of Medicine, 294, 365-369.

Janerich, D. T. (1972). Anencephaly and maternal age. American Journal of Epidemiology, 95, 319-326.
Janerich, D. T. (1973a). Epidemic waves in the prevalence of anencephaly and spina bifida in New York State. Teratology, 8 , 253-256.

Janerich, D. T. (1973b). Maternal age and spina bifida: longitudinal versus cross-sectional analysis. American Journal of Epidemio$\log y, 96,389-395$.

Janerich, D. T. (1974). Endocrine dysfunction and anencephaly and spina bifida. American Journal of Epidemiology, 99, 1-6.

Knox, E. G. (1974). Twins and neural tube defects. British Journal of Preventive and Social Medicine, 28, 73-80.

Leck, I. (1972). The etiology of human malformations: insights from epidemiology. Teratology, 5, 303-314.

MacMahon, B., and Pugh, T. F. (1970). Epidemiology: Principles and Methods. Little, Brown, Boston.

MacMahon, B., and Yen, S. (1971). Unrecognized epidemic of anencephaly and spina bifida. Lancet, 1, 31-33.

Naggan, L. (1971). Anencephaly and spina bifida in Israel. Pediatrics, 47, 577-586.

Nance, W. W. (1969). Anencephaly and spina bifida: a possible example of cytoplasmic inheritance in man. Nature, 224, 373375.

Roberts, C. J., and Lloyd, S. (1973). Area differences in spontaneous abortion rates in South Wales and their relation to neural tube defect incidence. British Medical Journal, 4, 20-22.

Rogers, S. C., and Morris, M. (1971). Infant mortality from spina bifida, congenital hydrocephaly, monstrosity and the cardiovascular system in England and Wales. Annals of Human Genetics, 34, 295-305.

Smithells, R. W., Sheppard, S., and Schorah, C. J. (1976). Vitamin deficiences and neural tube defects. Archives of Disease in Childhood, 51, 944-950.

Wilson, J. S. P., and Vallance-Owen, J. (1966). Congenital deformities and insulin antagonism. Lancet, 2, 940-941.

Yen, S., and MacMahon, B. (1968). Genetics of anencephaly and spina bifida? Lancet, 2, 623-626.

Requests for reprints to Dr Dwight T. Janerich, New York State Department of Health, Cancer Control Bureau, Empire State Plaza, Tower Building, Albany, New York 12237, U.S.A. 